\title{
ATTENDING LECTURES WITHOUT BARRIERS: THE CASE FOR STUDENTS WHO ARE DEAF AND HARD OF HEARING
}

\author{
Magda Nikolaraizi ${ }^{1^{*}}$ and Christina Kofidou ${ }^{2^{*}}$ \\ ${ }^{1}$ Associate Professor, Department of Special Education, University of Thessaly, Greece, \\ mnikolar@uth.gr \\ ${ }^{2} \mathrm{PhD}$ student, Department of Special Education, University of Thessaly, Greece, \\ ckofidou@sed.uth.gr \\ ${ }^{*}$ Corresponding author
}

\begin{abstract}
The access and participation of deaf and hard of hearing $(\mathrm{DHH})$ students in higher education is a challenging issue. Students who are DHH face several barriers especially in relation to their access and participation during lectures. Several factors are associated with these barriers, which are associated with the level of accessibility of higher education institutions (HEls). The aim of the present study is to examine the experiences of students who are $\mathrm{DHH}$ regarding their access during lectures. Twenty semi-structured interviews were conducted with DHH students, aged 21 to 40 years, attending several departments of HEls in Greece. Thematic analysis was used to analyse the data and the software ATLAS-ti.8 was used to process and analyze the data collected from students' interviews. The analysis of the data indicated that the most important factors that were associated with the students' academic access were environmental factors, the availability and quality of support services and the lecturers' practices. The discussion focuses on the importance of support services and the need for accessible institutions. Therefore, it is of major importance for all HEls that want to be accessible and inclusive for students who are DHH to develop services, awareness programs and make adjustments in order to enhance the access of students who are $\mathrm{DHH}$ especially during lectures.
\end{abstract}

Keywords: deaf, hard of hearing, access, higher education, inclusion.

\section{INTRODUCTION}

Higher education institutions (HEls) are very challenging for students who are deaf or hard of hearing (DHH). They face several barriers that hinder their access and inclusion in the university context, often resulting in alienation and abandonment (Bisol, Valentini, Simioni, Zanchin \& Dinham, 2010; Lang, 2002; Richardson, 2001). These challenges are associated with the level of accessibility of HEls as well as the individual characteristics of the students (Albertini, Kelly \& Matchett, 2012; Cawthon, Nickols, \& Collier, 2009; Hyde et al., 2016; Lang, 2002; Layton \& Lock, 2003; Luckner \& Becker, 2013; Stinson, Liu, Saur, \& Long, 1996).

The present paper focuses on the academic access of students who are $\mathrm{DHH}$ and specific on their academic access during lectures, which is one of the main challenges that they face due to the communication barriers that exist (Hyde et al., 2009; Stinson, 1987). Previous research has indicated that students who are DHH faced many challenges in relation to communication and learning during lectures, which are associated with several factors such as environmental factors, the level of support services and the lecturers' awareness or willingness regarding practices that could enhance the students' access and participation (Bell, 2013; Powell, 2011; Hyde et al., 2009; Nikolaraizi, Kofidou, \& Hyde, 2019).

The aim of the present study is to further examine the access of students who are DHH during lectures by encouraging them to share their own experiences in HEls. 


\section{METHODOLOGY}

\subsection{Participants}

Twenty DHH students attending HEls were interviewed, 12 women and 8 men, 21 to 40 years old. Half of the participants were using two hearing aids, $10.0 \%$ had one hearing aid, $40.0 \%$ had a cochlear implant and one participant did not use any listening device. The students attended a variety of departments. Specifically, nine participants attended courses in Humanitarian, Legal, and Social sciences, five students attended Health and Life Sciences, three students Economics and Informatics and 15,0\% Applied and Technological Sciences.

\begin{tabular}{ccc}
\hline Discipline & Participants & $\%$ \\
\hline Humanitarian, Legal \& Social & 9 & 45.0 \\
\hline Applied \& Technological & 3 & 15.0 \\
\hline Health and Life & 5 & 25.0 \\
\hline Economics & 3 & 15.0 \\
\hline Total & 20 & 100,0
\end{tabular}

Fig. 3. Science discipline the participants are attending

\subsubsection{Research tool}

The research tool consisted of an interview guide, which was developed by the researchers based on the review of the relevant literature. The interview guide included two sections. The first section included demographic data and the second one included questions related to the following: Environment, Support Services, Lecturers' Educational Practices, Fellow students' Communication Practices, and Understanding Lecture. In this paper, the results regarding the environment, the support services, the lecturers' educational practices are analysed.

\subsubsection{Procedure}

The participants were contacted by emails and through Facebook. All interviews were held by distance via Skype application or by Facebook video chat. The average duration of each interview was about 30 to 60 minutes. Three interviews were facilitated by a Greek Sign Language (GSL) interpreter, while the rest of the interviews took place in oral Greek. The interviews with the 20 students were videotaped with the participants' consent.

\subsubsection{Data Analysis}

All interviews were translated in Greek and were transcribed. The ATLAS.ti version 8 software has been used for the analysis of students' interviews, a software helpful for exploring the data, coding, working with comments and memos, querying data, creating networks and reports (Friese, 2019). The interviews were processed and analyzed using a thematic analysis (Bryman, 2017; Creswell, 2016) and a two-stage coding procedure (first-cycle coding and second-cycle coding) (Friese, 2019; Miles, Huberman, \& Saldaña, 2014; Saldaña, 2013).

In specific, at the first-stage of coding, quotations were found, which were attached to codes. Each code was connected with a comment-definition, so that the researchers always had in their mind the meaning of each code. Followingly, at the second-stage of coding, the codes that were related with the project were merged to categories and subcategories. It was made sure that each category was clearly discerned from all other categories and all subcategories inside the category were also discerned from each other (Friese, 2019).

\section{RESULTS}

\subsection{Environment}

Many participants commented on environmental factors affecting their academic access. First of all, they referred to classroom acoustics, the lighting conditions and the seating arrangements: 
"The acoustics are always good. In small classrooms we can hear clearly the instructors and in large classrooms there is a microphone" (P8, Q: 8:5).

"If I seat in upper seats, I don't have good acoustics, especially in amphitheaters, and when there is no microphone, you can only hear whispers. In this case I am having a hard time hearing the instructor" (P15, Q: 15:5).

"There are roads with traffic near the university, I can hear many external sounds, like motorcycles, which prevent me from hearing the lecturer" (P3, Q: 3:4).

Apart from the role of acoustics, the participants referred to the lighting conditions that can also influence their academic access:

"Some instructors prefer a dimmer lighting in order to project slides more clearly. Their lecture is oral and since I can't lipread, I try to grasp what I can from the projection".

Furthermore, some of the participants commented that the seating arrangements affect their academic access, such as if they allow them to keep eye contact with classmates, instructors and the interpreter:

"Desks are usually arranged one behind the other, which makes me have to turn my head left and right, in order to receive as much information as I can" (P2, Q:2:8).

"Most desks are stable, thus I cannot keep good eye contact" (P5, Q:5:6).

\subsection{Support Services}

Some participants commented on the support services that were available to HEls for them. The participants who wanted a GSL interpreter referred to the availability and the effectiveness of the interpreter:

"I get the information I need through the interpreter, if there is one" (P20, Q: 20:23). "If there is not an interpreter in the classroom, it is difficult for me to participate" (P20, Q: 20:50).

The participants commented on interpreters' effectiveness to convey oral messages accurately and completely:

"It was pretty common for an interpreter not to understand the lecture. Some courses are just difficult, they have a very specific terminology" (P6, Q: 6:105).

"In many cases interpreters do not understand the lecture, making the conveyance of information from spoken Greek into Greek Sign Language problematic. They would interrupt the instructor to ask for clarifications" (P7, Q: 7:30).

Furthermore, the participants emphasized the value of taking notes from their fellow students, since they often had difficulties attending and writing at the same time:

"My classmates and friends offer a lot of help, they explain what the lecturer has told or they show me their notes, in order to copy them" (P5, Q: 5:5).

"I have often taken notes from my classmates. They are aware of my not hearing well, so I have a friend which provides explanations for me and passes on her notes. I usually ask notes from her" (P18, Q: 18:6).

Some students referred to the quality of their fellow students' notes:

"Sometimes, if I take a classmate's notes, some words or phrases are illegible. At times they cannot read them either, although these are notes they have written themselves. This happens if the course's difficulty is high" (P15, Q: 15:66).

"The quality of notes taken depends on the student. Students take notes for themselves, not for me" (P17, Q: 17:18).

"They will not make an effort to explain something better, just to help me understand. If I ask for explanations, they will provide them to me personally" (P17, Q: 17:19).

\subsection{Educational Practices}

Some DHH students commented on instructors' educational practices applied during the lectures. First of all, they mentioned that their instructors checked their comprehension, indicated the change of subject during the lectures, permitted lecture recording:

"Some instructors adjust their way of teaching to facilitate my participation. For example, they would interrupt 
the flow of the lecture to ask me if I have understood what has been told" (P7, Q: 7:43).

"I am usually recording the lecture. Instructors allow it" (P10, Q: 10:78).

Furthermore, the participants referred to the use of visual tools during the lectures and the reasons for using them or not:

"Certain instructors write notes on the board in bullet points, which is perfect, because it helps me to stay focused. Other instructors just make quick, unstructured notes, making it really difficult for me to understand" (P17, Q: 17:58).

Moreover, DHH students commented on the availability of PowerPoint presentations:

"Unfortunately, many lecturers, particularly in workshops, upload their presentations too late, usually one or two weeks prior to our exam period. In theoretical courses the presentations are uploaded one or two months prior to our exams" (P5, Q: 5:28).

"There are instructors who upload presentations, but ask us not to post them anywhere" (P16, Q: 16:30). "Most of them do not upload presentations at all, making us taking pictures of them, even secretly" (P16, Q: 16:31).

"On the E-class platform there are slides available, in case someone wants to study more" (P5, Q: 5:36).

\section{DISCUSSION}

Based on the results of this study, various factors seemed to be important for the students' access. Environmental factors can impact DHH students' academic access. The design of the classroom and mostly the acoustics are fundamental and may cause problems to students' access and learning (Chin-Quee \& Penton, 2004; Pavčeková, Rychtáriková, \&Tomašovič, 2009). Furthermore, support services play an important role. The use, suitability and adequacy of the support services are fundamental for the effective academic access of $\mathrm{DHH}$ students, taking into account the communication barriers that may be experienced by students who are DHH (Stinson et al., 1996).

In specific, the performance skills of the interpreter (Schick, Williams, \& Kupermintz, 2006) as well as the level of collaboration between the interpreter and the lectures play an important role in their academic access. Furthermore, note taking is essential for DHH students, ensuring equal access to the classroom information (Hastings et al., 1997). A good note taker is concerned with the appearance of his notes, providing legible and attractive notes that facilitate reading comprehension (Hastings et al., 1997).

In our study the participants relied on interpreters who did their practicum or peers volunteers who acted as note takers rather than professionals. In agreement with previous studies (Bisol at al., 2010; Powell, 2011) the students felt often dissatisfied with this type of support, because the note takers lacked the expected level of professionalism and provided meager notes or the interpreters were not suitably skilled.

Finally, the role and skills of lecturers are very important for the access of DHH students. Students who are $\mathrm{DHH}$ value as effective teachers those who understand deaf people and deafness as an educational condition and use practices as well as modify their instruction to meet their students' needs (Lang, 2002; Lang, McKee, \& Conner, 1993). In our study, the participants' experiences were mixed and they felt that some lecturers made efforts to adjust, while other lecturers did not seem to be aware of their needs.

In conclusion, the academic access of students who are $\mathrm{DHH}$ is a complex issue and the provision of accessible experiences that respond to students' diversities and needs, culture and values (Adoyo, 2007) is not an easy task. Therefore, an ongoing effort is required from HEls that want to promote an inclusive philosophy, in order to develop and provide accessible lectures to students who are $\mathrm{DHH}$.

\section{REFERENCE LIST}

Adoyo, P. O. (2007). Educating deaf children in an inclusive setting in Kenya: Challenges and considerations. Electronic Journal for Inclusive Education, 2(2), Retrieved from https://corescholar.libraries.wright.edu/ejie/vol2/iss2/8/

Albertini, J. A., Kelly, R. R., \& Matchett, M. K. (2012). Personal factors that influence deaf college students' academic success. Journal of Deaf Studies and Deaf Education 17(1), 85-101. 
https://doi.org/10.1093/deafed/enr016

Bell, D. (2013). Investigating teaching and learning support for students with hearing impairment at a university in the Western Cape (Doctoral dissertation). Stellenbosch University. https://doi.org/10.13140/RG.2.1.2069.9687

Bisol, C. A., Valentini, C. B., Simioni, J. L., Zanchin, J., \& Dinham, R. (2010). Deaf students in higher education: reflections on inclusion. Cadernos de Pesquisa, 40(139), 147-172. https://doi.org/10.1590/S0100-15742010000100008

Bryman, A. (2017). Social research methods. Oxford University Press

Cawthon, S. W., Nichols, S. K. \& Collier, M. (2009). Facilitating access: What information do Texas postsecondary institutions provide on accommodations and services for students who are deaf or hard of hearing? American Annals of the Deaf, 153(5), 450-460.

Chin-Quee, D., \& Penton, R. L. S. (2004). Design of a classroom for deaf / hearing impaired student educators. Canadian Acoustics, 32(3), 36-37. Retrieved from https://jcaa.caaaca.ca/index.php/jcaa/article/view/1615

Creswell, J. W. (2016). Educational research: Planning, conducting, and evaluating quantitative and qualitative research. Pearson.

Friese, S. (2019). Grounded theory analysis and CAQDAS: A happy pairing or remodeling GT to QDA? In A. Bryant, \& K., Charmaz, (Eds), The SAGE handbook of current developments in Grounded Theory (pp. 282-313). London, UK: SAGE Publications.

Hastings, D., Brecklin, K., Cermak, S., Reynolds, R., Rosen, H., \& Wilson, J. (1997). Note taking for deaf and hard of hearing students: A report of the National Task Force on Quality of Services in the Postsecondary Education of Deaf and Hard of Hearing Students (ERIC Document Reproduction Service No. ED 437 777). Rochester, NY: Northeast Technical Assistance Center, Rochester Institute of Technology.

Hyde, M., Nikolaraizi, M., Powell, D., \& Stinson, M. (2016). Critical factors toward the inclusion of deaf and hard-of-hearing students in higher education. In M. Marschark, V. Lampropoulou, \& E. K. Skordilis (Eds.), Diversity in Deaf Education. New York, NY, United States of America: Oxford University Press.

Hyde, M., Punch, R., Power D., Hartley J., Neale J., \& Brennan L. (2009). The experiences of deaf and hard of hearing students at a Queensland University: 1985-2005. Higher Education Research \& Development, 28(1), 85-98, https://doi.org/10.1080/07294360802444388

Lang, H. G. (2002). Higher Education for Deaf Students: Research Priorities in the New Millennium, Journal of Deaf Studies and Deaf Education, 7(4), 267-280. doi:10.1093/deafed/7.4.267

Lang, H. G, McKee, B. G, \& Conner, K. N. (1993). Characteristics of effective teachers: A descriptive study of perceptions of faculty and deaf college students. American Annals of the Deaf, 138, 252-259.

Layton, C. A., \& Lock, R. H. (2003). Reasoning and self-advocacy for postsecondary students with learning disabilities. Learning Disabilities, 12(2), 49-55.

Luckner, J. L., \& Becker, S. J. (2013). Fostering skills in self-advocacy: A key to access in school and beyond. Odyssey: New Directions in Deaf Education, 14, 34-38.

Miles, M. B., \& Huberman, A. M., \& Saldaña, J. (2014). Qualitative data analysis. A methods sourcebook (3 ${ }^{\text {rd }}$ ed.). Thousand Oaks, CA: Sage Publications.

Nikolaraizi, M., Kofidou, Ch., \& Hyde, M. (2019). The role of self-advocacy in academic access for students who are deaf or hard of hearing in higher education: Insights from educators across world. In S. Halder, V. Argyropoulos (Eds), Inclusion, equity and access for individuals with disabilities (pp. 383408). Singapore: Palgrave Macmillan. https://doi.org/10.1007/978-981-13-5962-0 19

Pavčeková, M., Rychtáriková, M., \& Tomašovič, P. (2009). Acoustical comfort predictions in classrooms with two simultaneous sound sources. Slovak Journal of Civil Engineering, 2, 17-25. Retrieved from https://www.svf.stuba.sk/buxus/docs/sjce/2009/2009 2/file5.pdf

Powell, D. R. A. (2011). Floating in the mainstream: New Zealand deaf students' learning and social participation experiences in tertiary education (Doctoral dissertation). Griffith University, Brisbane, Australia. Retrieved from https://www120.secure.griffith.edu.au/rch/file/50908dc2-8eda-37b0-aeb7- 


\section{3daa656a3a/1/Powell 2011 02Thesis.pdf}

Richardson, J. T. E. (2001). The representation and attainment of students with a hearing loss in higher education. Studies in Higher Education, 26(2), 183-204. doi:10.1080/03075070120052107

Saldaña, J. (2013). The coding manual for qualitative researchers ( $2^{\text {nd }}$ ed.). London, UK: SAGE Publications.

Schick, B., Williams, K., \& Kupermintz, H. (2006). Look who's being left behind: Educational interpreters and access to education for deaf and hard of hearing students. Journal of Deaf Studies and Deaf Education, 11(1), 3-20. doi: 10.1093/deafed/enj007

Stinson, M. S., Liu, Y., Saur, R., \& Long, G. (1996). Deaf college students' perceptions of communication in mainstreamed classes. Journal of Deaf Studies and Deaf Education, 1(1), 140-51. 